\title{
1 Antimicrobial silver inhibits bacterial movement and stalls 2 flagellar motor
}

Benjamin Russell ${ }^{1}$, Ariel Rogers ${ }^{1}$, Matthew Kurilich ${ }^{1}$, Venkata Rao Krishnamurthi ${ }^{1}$, Jingyi Chen ${ }^{2,3}$, Yong Wang ${ }^{1,3,4^{*}}$

${ }^{1}$ Department of Physics, ${ }^{2}$ Department of Chemistry and Biochemistry, ${ }^{3}$ MicroelectronicsPhotonics Program, ${ }^{4}$ Cell and Molecular Biology Program, University of Arkansas, Fayetteville, AR, 72701, USA.

*To whom correspondence should be addressed: yongwang@uark.edu (YW).

Silver $(\mathrm{Ag})$ has been gaining broad attention due to their antimicrobial activities and the increasing resistance of bacteria to commonly prescribed antibiotics. However, various aspects of the antimicrobial mechanism of Ag have not been understood, including how silver affects the motility of bacteria, a factor that is intimately related to bacterial virulence. Here we report our study on the antibiotic effects of $\mathrm{Ag}^{+}$ions on the motility of $E$. coli bacteria using swimming and tethering assays. We observed that the bacteria slowed down dramatically when subjected to $\mathrm{Ag}^{+}$ions, providing direct evidence showing that $\mathrm{Ag}$ inhibits the motility of bacteria. In addition, through tethering assays, we monitored the rotation of flagellar motors and observed that the tumbling frequency of bacteria increased significantly in the presence of $\mathrm{Ag}^{+}$ions. Furthermore, the rotation of bacteria in the tethering assays were analyzed using hidden Markov model (HMM); and we found that $\mathrm{Ag}^{+}$-treatment led to a significant decrease in the tumbling-to-running transition rate of the bacteria, suggesting that the rotation of bacterial flagellar motors was stalled by $\mathrm{Ag}^{+}$ions. This work provided a new quantitative understanding on the mechanism of Ag-based antimicrobial agents in bacterial motility.

Keywords: hidden Markov model, antibiotics, E. coli, motility, tethering assay. 


\section{Introduction}

The rising prevalence of antibiotic-resistance in harmful microbes due to overuse of conventional antibiotics has become a serious global concern for public health[1, 2, 3], posing the need for different approaches for fighting against drug-resistant microbes[4, 5]. Recent research in the past two decades revisited the antimicrobial activities of noble metals, such as silver ( $\mathrm{Ag})$, in different forms - including ions and nanoparticles - and has uncovered their strong capacity for suppressing bacterial growth and killing bacteria[6, 7, 8]. Exciting progress has been made towards understanding the antimicrobial mechanism of $\mathrm{Ag}$, suggesting that $\mathrm{Ag}$ caused multidirectional damages to bacteria, including DNA damage, membrane disruption, free radical generation (ROS), and loss of ATP production[7, 9, 10, 11, 12, 13]. However, various aspects of the antimicrobial mechanism of $\mathrm{Ag}$ remain elusive, especially that the temporal resolution for understanding the Ag-caused damages in bacteria $\mathrm{Ag}$ is still limited[7, 14, 15]. This includes how silver affects the motility of bacteria, which is tightly coupled to bacterial virulence[16].

Motility is essential to many bacteria for detecting and pursuing nutrients, as well as avoiding and fleeing from toxicants. Certain bacteria, such as Escherichia coli (E. coli), use flagella to move in aqueous environments[17]. E. coli flagella are filaments extending outward from the bacteria[18]. The flagella are connected to and driven by motors embedded in the bacterial membrane through hooks[19]. For E. coli-peritrichous bacteria with flagella covering their entire surfaces, their movement depends on the rotation direction of their flagella[17, 19]. When flagella rotate counterclockwise (CCW), they are bundled and propel the bacteria to move directionally (i.e., running) for purposeful movement toward chemical attractants or away from repellents[17, 20]; when flagella rotate clockwise $(\mathrm{CW})$, they are splayed out, resulting in reorientation (i.e., tumbling) of the bacteria[17, 20]. The $E$. coli flagella contains mainly three parts: the filament, the hook, and the basal body[17, 20]. The basal body consists of several rings, some of which (e.g., MS ring and C ring) are essential components of the flagellar motor for driving the rotation of the flagella[17]. Structurally, the flagellar motor involves both the stator proteins (e.g., MotA and MotB) and the rotor proteins (e.g., FliG, FliM, and FliN), which also play critical roles in the torque generation of the motor[17]. Functionally, the CW/CCW direction of the flagellar motor's rotations relies on another set of chemotaxis proteins (e.g., CheY, CheZ, CheA, CheW, CheR, and CheB). For example, the flagellar motor switches from CCW rotation to $\mathrm{CW}$ rotation when the phosphorylated response regulator CheY binds to the flagellar motor[21].

As $\mathrm{Ag}$ in various forms (e.g., ions, nanoparticles) suppresses and kills bacteria, we hypothesized that the motility of bacteria is significantly affected by Ag. This hypothesis is indirectly supported by evidence from previous studies. For example, Ivask et al. performed liquid-culture-based highthroughput growth assays for a library of single-gene-deletion strains of $E$. coli, and found that a series of flagella-related mutants (e.g., fliG, fliM, flgF, flgG, etc., which are involved in the assembly and function of flagella) were sensitive to $\mathrm{Ag}^{+}$ions and $\mathrm{Ag}$ nanoparticles[13]. Also, platebased chemical genetic screening assays on a similar library identified and confirmed some flagella-related genes (e.g., flgA, flgD, flgJ, flgK, fliC, fliE, fliL, fliP, fliR, and motB)[22]. In addition, 
universal regulatory proteins in bacteria, such as histone-like nucleoid structuring (H-NS) proteins, which regulate bacterial chemotaxis and motility[14, 22, 23, 24, 25]. Furthermore, although mixed results were present, plate-based swimming and swarming motility assays suggested that $\mathrm{Ag}$ could change the motility of bacteria under certain conditions[26]. On the other hand, $\mathrm{Ag}^{+}$ions have been used for staining bacterial flagella for decades[27], implying that $\mathrm{Ag}^{+}$ions interact with flagella.

However, few studies on real-time observation and quantification of $\mathrm{Ag}^{\prime}$ s effects on bacterial movement are presented in the literature[7, 28]. In this work, we investigated the antibiotic effects of $\mathrm{Ag}^{+}$ions on the swimming behavior of $E$. coli bacteria based on microscopic imaging, with a temporal resolution of $15-50 \mathrm{~ms}$. $\mathrm{Ag}^{+}$ions were chosen for two reasons. First, $\mathrm{Ag}^{+}$ions are effective at suppressing and killing bacteria[6, 10, 29]. Second, the release of $\mathrm{Ag}^{+}$ions from $\mathrm{AgNPs}$ is one major contribution to the toxicity of AgNPs[7]. Through the swimming assays, we provided direct evidence showing that $\mathrm{Ag}$ inhibits the motility of bacteria. In addition, we monitored the rotation of flagellar motors of $\mathrm{E}$. coli bacteria though tethering assays in the absence and presence of $\mathrm{Ag}^{+}$ions, directly observing that $\mathrm{Ag}^{+}$ions increased the frequency of bacterial tumbling. Furthermore, based on hidden Markov model (HMM) analysis, we found that $\mathrm{Ag}^{+}-$ treatment caused bacterial transition rate from the tumbling state to the running state to decrease significantly, suggesting that the rotation of bacterial flagellar motors was stalled by $\mathrm{Ag}^{+}$ ions. This real-time quantification analysis by high temporal resolution microscopic imaging provides direct evidences of Ag effects on bacterial mobility.

\section{Materials and Methods}

101

\section{Bacterial strain and growth}

An E. coli K12-derived strain from Refs. [15, 23, 30, 31] was used in this study. The strain has been used in previous investigations of the antimicrobial activities of $\mathrm{Ag}^{+}$ions and $\mathrm{AgNPs}[15,23,31]$. This strain has the hns gene knocked out from the chromosomal DNA, but supplemented with a plasmid encoding for the H-NS protein fused to mEos3.2 fluorescent protein[32] and for resistance to kanamycin and chloramphenicol[15, 23, 30,31].

Each experiment started with inoculating a single bacterial colony into $5 \mathrm{~mL}$ of Luria Broth (LB) medium supplemented with kanamycin and chloramphenicol $(50 \mu \mathrm{g} / \mathrm{mL}$ and $34 \mu \mathrm{g} / \mathrm{mL}$, respectively)[23]. The liquid culture was grown at $37^{\circ} \mathrm{C}$ in a shaking incubator (250 RPM) overnight. On the second day, the overnight culture was diluted by $5000 \times$ into $5 \mathrm{~mL}$ of fresh LB medium with the antibiotics. The new culture was grown at $32^{\circ} \mathrm{C}[33,34,35]$ in the shaking incubator until the bacterial culture reached the mid-exponential phase $\left(O D_{600} \approx 0.3\right)$, followed by measurements as described below.

\section{Phase contrast microscopy}


Measurements in the swimming and tethering assays were done at room temperature using phase contrast microscopy on an Olympus IX-73 inverted microscope equipped with a 100×, $\mathrm{NA}=1.25$ phase-contrast, oil-immersion objective (Olympus) and an EMCCD camera (Andor Technology). The microscope and data acquisition was controlled using Micro-Manager[36, 37]. The effective pixel size of recorded images/movies was $0.16 \mu \mathrm{m}$.

\section{Swimming assay}

In swimming assay experiments, $E$. coli bacteria at $\mathrm{OD}_{600} \approx 0.3$ were treated with $\mathrm{Ag}^{+}$ions at 30 $\mu \mathrm{M}$ or $40 \mu \mathrm{M}$ for 1,2 , and $4 \mathrm{hr}$, which clearly showed suppressed growth. At each time point, 2 $\mathrm{mL}$ of the bacterial culture were transferred to a cleaned glass-bottom Petri-dish, followed by monitoring and recording the free swimming of the bacteria using phase-contrast microscopy. The swimming of untreated bacteria (i.e., before the addition of $\mathrm{Ag}^{+}$ions, or $0 \mathrm{hr}$ ) was monitored and used as negative controls. The exposure time was set to $30 \mathrm{~ms}$, while the actual time interval between adjacent frames of the acquired movies was $54 \mathrm{~ms}$. The acquired movies of freely swimming bacteria were processed in ImageJ by inversion, smoothing, and background subtraction[38, 39], followed by automated identification and localization of the bacteria using custom-written MATLAB programs[40]. The localizations of the bacteria were then linked into trajectories following standard algorithms[40, 41, 42], using a maximum displacement between adjacent frames of $1.92 \mu \mathrm{m}$ (12 pixels), a memory of 0 frame (i.e., no gap), and a minimum length of 12 frames. The identified trajectories further went through a manual quality control process by removing the bacteria that were stuck on the glass surface or formed large clumps.

The trajectories of the bacteria in the freely swimming assays were further analyzed using custom-written or open-source Python programs. For example, the instantaneous velocities were calculated from the trajectories $\mathbf{r}(t)$ of the bacteria, $v(t)=\left|\frac{\mathbf{r}(t+\Delta t)-\mathbf{r}(t)}{\Delta t}\right|$, where $\Delta t=54$ ms. In addition, we estimated the maximum chord-to-arc ratio $\left(\gamma_{C A}^{M}\right)$ for each trajectory, inspired by TumbleScore[43], $\gamma_{C A}^{M}=\frac{\max _{i, j}\left(\left|\mathbf{r}_{i}-\mathbf{r}_{j}\right|\right)}{\sum_{i}\left|\mathbf{r}_{i+1}-\mathbf{r}_{i}\right|}$, where $\mathbf{r}_{i}$ and $\mathbf{r}_{j}$ were positions of a single trajectory. Furthermore, the changing rates of swimming directions $\Omega$ were estimated directly from the trajectories[43, 44, 45], $\Omega_{i}=\cos ^{-1}\left(\frac{\mathbf{v}_{i+1} \cdot \mathbf{v}_{i}}{\left|\mathbf{v}_{i+1}\right|\left|\mathbf{v}_{i}\right|}\right)$. Lastly, we calculated the ensemble mean-squaredisplacement (MSD) for each sample using the trackpy Python package[42], $\operatorname{MSD}(\tau)=$ $\left\langle(\mathbf{r}(t+\tau)-\mathbf{r}(t))^{2}\right\rangle$, where $\tau$ is the lag time.

\section{Tethering assay}

In tethering assay experiments[46, 47], E. coli bacteria in the mid-exponential phase $\left(\mathrm{OD}_{600} \approx 0.3\right)$ were tethered to glass-bottom Petri-dishes through their flagella. The tethering was achieved by coating the glass surface with biotinylated BSA, neutravidin, and biotinylated anti-FliC antibody sequentially[48, 49]. E. coli flagella bind to the anti-FliC antibody[50, 51], immobilizing the bacteria. The rotations of the tethered bacteria were monitored and recorded under phase contrast microscopy with an exposure time of $5 \mathrm{~ms}$ for 10000 frames without $\mathrm{Ag}^{+}$ions (the actual 
time interval between adjacent frames was $14.1 \mathrm{~ms})$. Then $\mathrm{Ag}^{+}$ions were directly added to the Petri-dish at a final concentration of $40 \mu \mathrm{M}$, followed by recording the rotations of the same bacteria for 50,000 to 100,000 frames. For negative controls, $\mathrm{LB}$ medium (instead of $\mathrm{Ag}^{+}$ions) was added to the Petri-dish and the rotations of the bacteria were recorded similarly. More than 10 replicate experiments were performed independently on different days.

Bacteria in the tethering assays were identified and characterized in each frame of the recorded movies using custom-written Python programs based on the scikit-image package[52]. From the primary axis of the identified bacteria, the orientation $\theta$ of the bacteria were obtained[53, 54], followed by estimating the angular velocities of the bacterial rotation $\omega=\Delta \theta / \Delta t$, where $\Delta t=$ $0.0141 \mathrm{~s}$. Note that frames containing other non-tethered bacteria invading the region of the tethered ones were removed from further analysis to ensure accuracy. The $\omega$-trajectories were analyzed using the hidden Markov model (HMM)[55], in which two states of the bacteria (running and tumbling) were assumed. In addition, Gaussian emission distributions were applied for the emission from the two states to the observable (i.e., angular velocities $\omega$ )[55]. The HMM analysis was done using the hmmlearn Python package. For each bacterium in the tethering assay, we fitted the HMM model using the $\omega$-trajectory before the addition of $\mathrm{Ag}^{+}$ions (or LB medium). Then the fitted model was used to predict the states for the data after the addition of $\mathrm{Ag}^{+}$ions (or LB medium), from which the probabilities of the two states and the transition rates were estimated[56].

\section{Results}

\section{Lower motibility of bacteria caused by $\mathrm{Ag}^{+}$ions}

We first examined the effects of $\mathrm{Ag}^{+}$ions on the motility of $E$. coli bacteria using swimming assays $[57,58,59]$. When $E$. coli bacteria at $\mathrm{OD}_{600} \approx 0.3$ were treated with $\mathrm{Ag}^{+}$ions at $40 \mu \mathrm{M}$ for 1,2 , and $4 \mathrm{hr}$, the cell density did not increase and the bacterial growth was suppressed. At each time point, $2 \mathrm{~mL}$ of the bacterial culture were taken to a glass-bottom Petri-dish, followed by monitoring and recording the free swimming of the bacteria using phase-contrast microscopy. Untreated bacteria (i.e., $0 \mathrm{hr}$ ) were measured as negative controls, and we observed that the treated bacteria were much slower (Movies M1 and M2). From the movies of the freely swimming bacteria, the trajectories $\mathbf{r}(t)$ of individual bacteria were obtained. 200 randomly chosen examples of trajectories for each experimental condition were shown in Fig. $1 \mathrm{~A}$, where longer traveling distances were observed for the untreated bacteria compared to the ones treated with $\mathrm{Ag}^{+}$ions. To see this difference more clearly, we plotted the corresponding rose graphs[43], in which the displacements of the bacteria from their individual initial positions were drawn, $\Delta \mathbf{r}^{0}(t)=\mathbf{r}(t)-\mathbf{r}(0) .300$ randomly chosen examples were shown in Fig. 1B, where the first 12 frames of the trajectories were shown to eliminate the differences due to different lengths of trajectories[43]. It is obvious that the motility of bacteria decreased significantly after the treatment with $\mathrm{Ag}^{+}$ions. Note that, although the trajectories are longer (up to 70 frames), only the first 12 frames were used in the rose graphs (Fig. 1B) to make direct comparisons. We quantified the mean and $90^{\text {th }}$ percentile of the displacements of the first 12 frames of all the 
trajectories in each condition, shown as solid and dotted circles in the rose graphs (Fig. 1B), respectively. We found that the two circles for untreated bacteria did not change significantly from 0 to $4 \mathrm{hr}$, indicating that the motility of the bacteria remained similar. In contrast, the treated bacteria showed much smaller radii for both the mean $\left(\overline{\Delta^{0} r}\right)$ and $90^{\text {th }}$ percentile circles, indicating $\mathrm{Ag}^{+}$-treatment led to lower bacterial motility. We also note that the radii slightly increased for longer treatment time, implying possible recovery of the bacteria as reported by our previous results[6, 15].

(B)
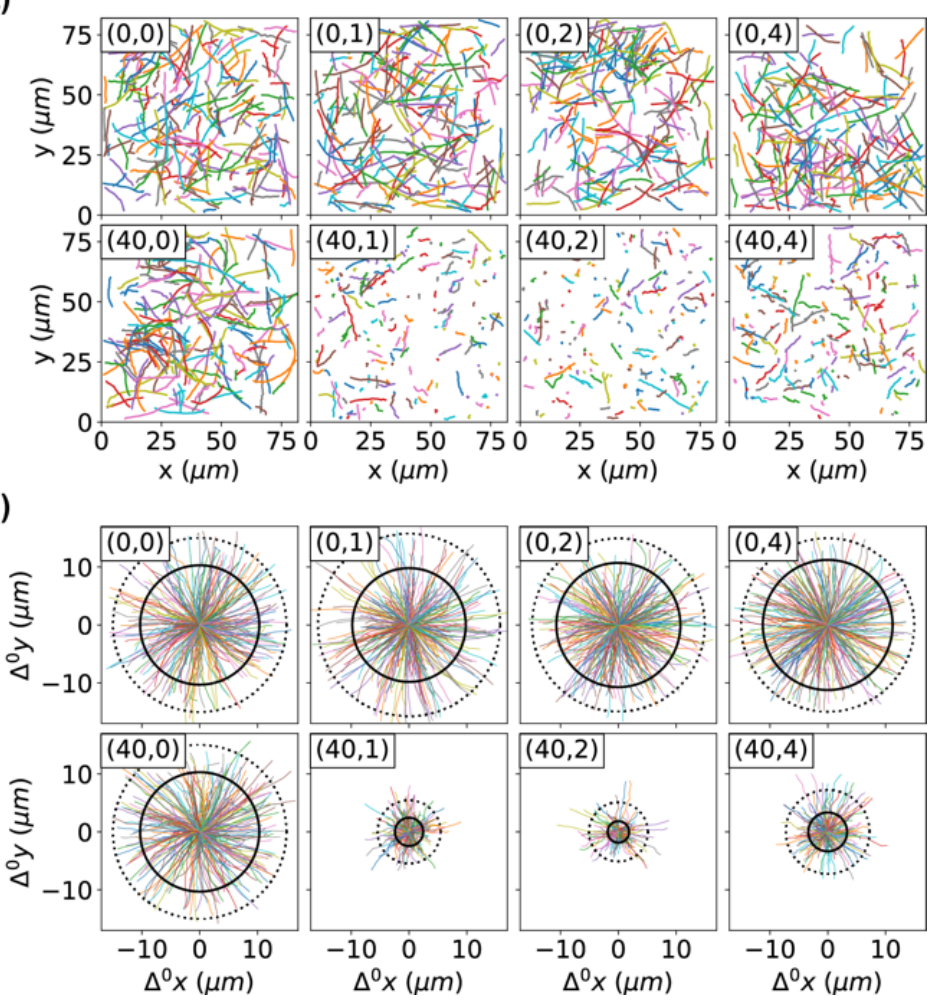

213 Figure 1. Motion of bacteria. (A) Trajectories of bacteria, untreated or treated by $\mathrm{Ag}^{+}$ions at 30 $\mu \mathrm{M}$ or $40 \mu \mathrm{M}$. Each sub-figure contains 200 randomly chosen trajectories, and is labeled by $\left(\mathrm{C}_{\mathrm{Ag}}\right.$, $\mathrm{T}_{\mathrm{tr}}$ ), where $\mathrm{C}_{\mathrm{Ag}}$ is the concentration of $\mathrm{Ag}^{+}$ions, and $\mathrm{T}_{\mathrm{tr}}$ is the treatment/incubation time. (B) Rose graphs of the first 12 frames of trajectories of bacteria, untreated or treated by $\mathrm{Ag}^{+}$ions at $30 \mu \mathrm{M}$ or $40 \mu \mathrm{M}$. Each sub-figure is labeled similar as in panel A. Under each condition, 300 randomly chosen examples of the trajectories were shown in color, while the mean and $90^{\text {th }}$ percentile of the displacements of the first 12 frames of all the trajectories were shown as solid and dotted circles, respectively.

The slower motion of bacteria caused by $\mathrm{Ag}^{+}$ions was further visualized in Fig. $2 \mathrm{~A}$ by plotting the radii of the mean circles in the rose graphs $\left(\overline{\Delta^{0} r}\right.$, Fig. 1B) as functions of treatment time. To further confirm that the $\mathrm{Ag}^{+}$ions inhibits the movement of bacteria, we calculated the instantaneous velocities of the bacteria directly from the trajectories, $v=|\mathbf{v}|=|\Delta \mathbf{r} / \Delta t|$ where $\Delta t=0.054 \mathrm{~s}$ is the time interval between adjacent frames. The dependence of the mean velocity 
on the treatment time is shown in Fig. 2B, showing the same trends as $\overline{\Delta^{0} r}$. In addition, we examined the distributions of the bacterial velocities (Fig. 2C), and observed a double-peak distribution (centered around 10 and $22 \mu \mathrm{m} / \mathrm{s}$ ) for the untreated bacteria ( $\mathrm{t}=0 \mathrm{hr}$ ), while $\mathrm{Ag}^{+}$treatment moved the peak to $\sim 2 \mu \mathrm{m} / \mathrm{s}$ (Fig. $2 \mathrm{C}$ ). Such significant shift in the velocity-distribution was absent in the negative controls (inset of Fig. $2 \mathrm{C}$ ). We also found that a second peak/shoulder (7-10 $\mathrm{mm} / \mathrm{s}$ ) emerged in the distributions of bacterial velocities at $4 \mathrm{hr}$ (Fig. 2C), consistent with the previously observed recovery of the bacteria[6, 15].

(A)

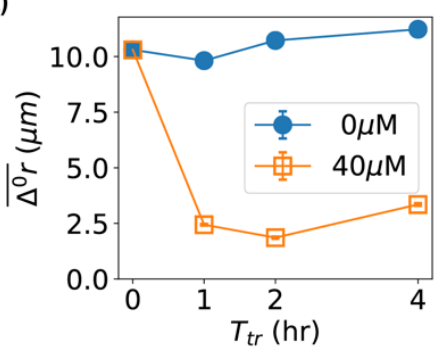

(D)

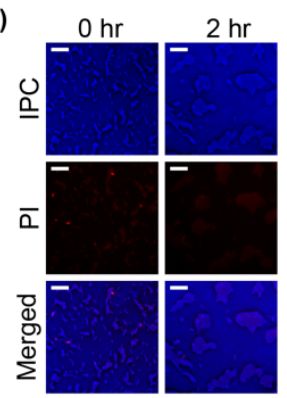

(B)

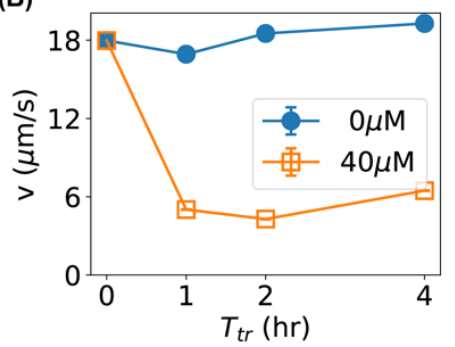

(E)
(C)

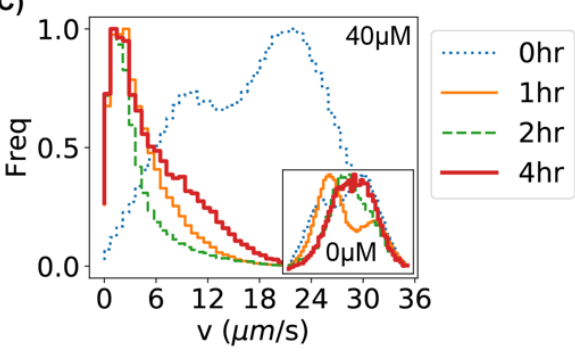

(F)

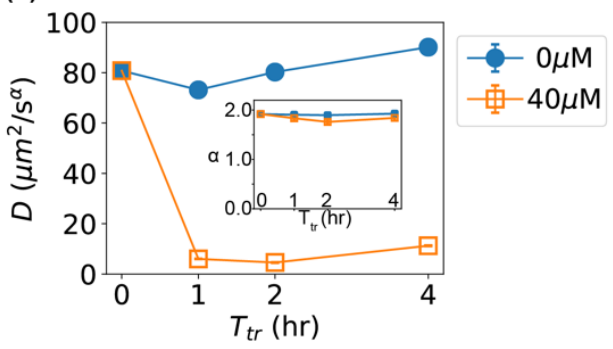

Figure 2. Lower motility of bacteria caused by $\mathrm{Ag}^{+}$ions. (A) The dependence of the mean displacements $\left(\overline{\Delta^{0} r}\right)$ of the first 12 frames of all trajectories of bacteria on incubation/treatment time in the absence $(0 \mu \mathrm{M})$ and presence of $\mathrm{Ag}^{+}$ions $(40 \mu \mathrm{M})$. (B) The dependence of the mean bacterial velocity on incubation/treatment time in the absence $(0 \mu \mathrm{M})$ and presence of $\mathrm{Ag}^{+}$ions $(40 \mu \mathrm{M})$. (C) Distributions of bacterial velocities in the presence of $\mathrm{Ag}^{+}$ions at $40 \mu \mathrm{M}$ for $0,1,2$, and $4 \mathrm{hr}$. Inset: the corresponding result for untreated bacteria $(0 \mu \mathrm{M})$. (D) Cell viability assay based on propidium iodide (PI) staining for untreated ( $0 \mathrm{hr}$, left column) and treated ( $2 \mathrm{hr}$, right column) bacteria. Top: inverted phase-contrast (IPC) images; Middle: fluorescence images due to PI staining; Bottom: merged IPC/PI images. Scale bar $=16 \mu \mathrm{m}$. (E) Log-log plot of mean-squaredisplacements (MSD) vs. lag time $(\tau)$ for trajectories of treated bacteria by $\mathrm{Ag}^{+}$ions at $40 \mu \mathrm{M}$ for $0,1,2$, and $4 \mathrm{hr}$. Inset: the corresponding result for untreated bacteria $(0 \mu \mathrm{M})$. (F) Dependencies of the generalized diffusion coefficient $D$ and the anomalous scaling exponent $\alpha$ (inset) on the incubation/treatment time $T_{\text {tr }}$.

As the bacterial velocities after $\mathrm{Ag}^{+}$-treatment were close to 0 (peaked at $\sim 2 \mu \mathrm{m} / \mathrm{s}$ ), one possibility is that the bacteria were killed by the bacteria at the given concentrations $(40 \mu \mathrm{M})$ of $\mathrm{Ag}^{+}$ions. However, this possibility was not favored for the following reasons. First, our previous work showed that the majority of bacteria treated with $60 \mu \mathrm{M} \mathrm{Ag}$ ions were alive, fighting against damages caused by $\mathrm{Ag}^{+}$ions and showing oscillations in their cell-lengths within $12 \mathrm{hr}[15]$. 
Second, cell viability assay based on propidium iodide staining[60] showed that the majority of treated bacteria were alive at $40 \mu \mathrm{M} \mathrm{Ag}^{+}$ions (Fig. 2D). Third, if the bacteria were killed, they would display random diffusion (Brownian motion) and the corresponding mean-squaredisplacement (MSD) would be proportional to the diffusion coefficient $(D)$ and the lag time $(\tau)$ and shows a slope of 1 in the log-log plot of MSD vs. $\tau$ (Fig. 2E) [61, 62]; however, fitting the experimental MSD curves (Fig. 2E) with $M S D=4 D \tau^{\alpha}$ ( $\alpha$ is the anomalous scaling exponent) showed that $\alpha$ remained $\approx 2$ in the presence of $\mathrm{Ag}^{+}$ions for various amounts of time (inset of Fig. $2 \mathrm{~F})$, indicating that the bacteria retained active motion after $\mathrm{Ag}^{+}$-treatment $[31,63]$. In contrast, the diffusion coefficient decreased significantly (Fig. 2F), following the same dependence on treatment time as the mean velocity of the bacteria (Figs. $2 \mathrm{~A}$ and $2 \mathrm{~B}$ ).

\section{Comparison of bacterial movement before and after $\mathrm{Ag}^{+}$-treatment}

We quantitatively compared the movement of bacteria before and after $\mathrm{Ag}^{+}$-treatment by examining the velocity autocorrelation. Briefly, we calculated the autocorrelations of the $x$ and $y$ components of bacterial velocities, $C_{v_{i}}(\tau)=\frac{\left\langle v_{i}(t+\tau) v_{i}(t)\right\rangle}{\left\langle v_{i}(t) v_{i}(t)\right\rangle}$, where $v_{i}=v_{x}$ or $v_{y}$ and $\tau$ is the lag time. For the untreated bacteria, the velocity autocorrelation did not change at different incubation time (insets of Figs. $3 \mathrm{~A}$ and $3 \mathrm{~B}$ ); in contrast, treating the bacteria with $\mathrm{Ag}^{+}$ions resulted in shifts to the left in the velocity autocorrelation (Figs. $3 A$ and $3 B$ ). The left-shift of the velocity autocorrelation suggested that the "persistence" time of the bacterial movement became shorter after $\mathrm{Ag}^{+}$-treatment, and the movement of bacteria became not as straight as that before treatment.

We also examined the maximum chord-to-arc ratio $\left(\gamma_{C A}^{M}\right)$ of the trajectories (inspired by TumbleScore[43]), $\gamma_{C A}^{M}=C^{M} / A$, where $C^{M}=\max _{i, j}\left(\left|\mathbf{r}_{i}-\mathbf{r}_{j}\right|\right)$ is the maximum chord length of a trajectory and $A=\sum_{i}\left|\mathbf{r}_{i+1}-\mathbf{r}_{i}\right|$ is the "arc" length of the trajectory. If a trajectory is straight, $\gamma_{C A}^{M} \approx 1$, while a trajectory dominated by directional changes gives $\gamma_{C A}^{M} \approx 0$; therefore, the maximum chord-to-arc ratio could be used as another indicator of the persistence of the trajectories. The cumulative distributions (CDF) of the $\gamma_{C A}^{M}$ of all the trajectories for bacteria untreated ( $0 \mu \mathrm{M}$ and/or $0 \mathrm{hr}$ ) or treated with $\mathrm{Ag}^{+}$ions for 1, 2, and $4 \mathrm{hr}$ are shown in Fig. $3 \mathrm{C}$. Compared to the untreated bacteria, the CDFs for treated bacteria rose up at lower $\gamma_{C A}^{M}$ values, indicating that $\mathrm{Ag}^{+}$ions led to higher fractions of lower $\gamma_{C A}^{M}$. This change was obvious by examining the time dependence of the mean values of $\gamma_{C A}^{M}$ (Fig. 3D). Note that a similar result was observed for the normalized maximum chord-to-arc ratio $\beta_{C A}^{M}=\gamma_{C A}^{M} / N$ where $N$ is the length of the trajectory.

Furthermore, we estimated the changing rate of moving directions directly from the trajectories, $\Omega=\cos ^{-1}\left(\mathbf{v}_{i+1} \cdot \mathbf{v}_{i} / v_{i+1} v_{i}\right)[43,44,45]$. The CDFs of $\Omega$ for all the trajectories of bacteria untreated ( $0 \mu \mathrm{M}$ and/or $0 \mathrm{hr}$ ) or treated with $\mathrm{Ag}^{+}$ions for 1,2 , and $4 \mathrm{hr}$ are shown in Fig. $3 \mathrm{E}$. We found that the CDFs lowered down after $\mathrm{Ag}^{+}$-treatment, indicating increased fraction of higher $\Omega$ values. This was confirmed by the time dependence of the mean values of $\Omega$ (Fig. 3F). All the three quantifications $\left(C_{v}, \gamma_{C A}^{M}\right.$, and $\Omega$ ) showed consistent result that the movement of bacteria became less persistent (i.e., less straight) after subjecting the bacteria to $\mathrm{Ag}^{+}$ions. 
(A)

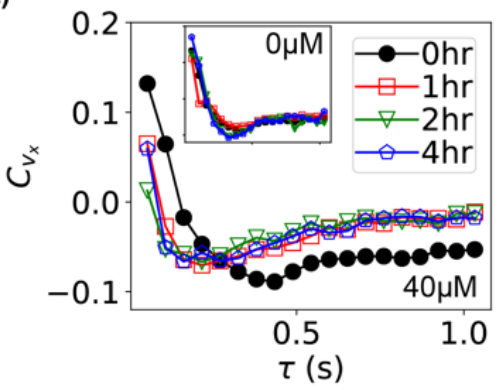

(C)

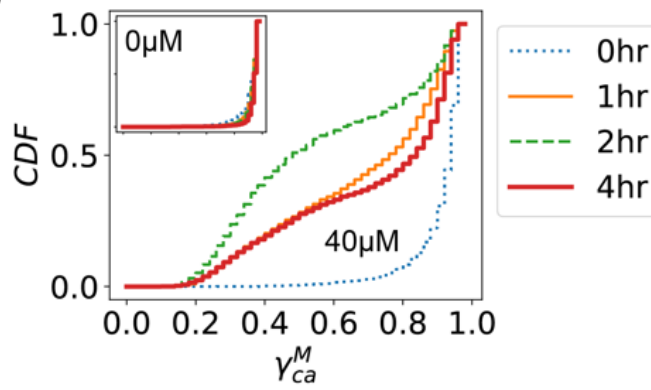

(E)
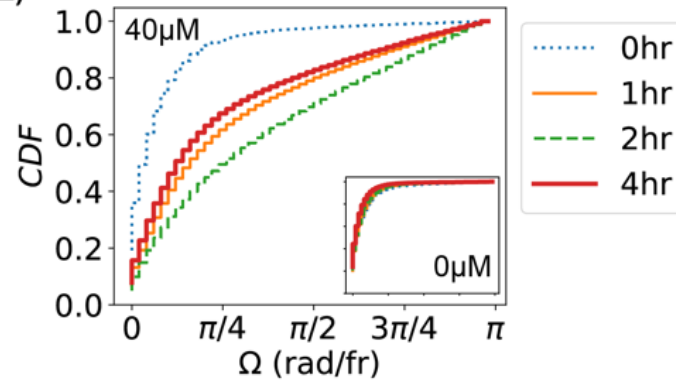

(B)

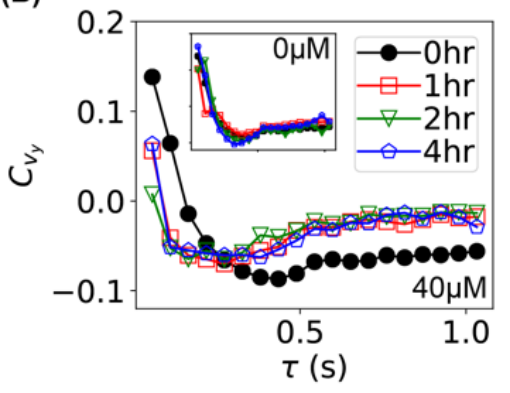

(D)

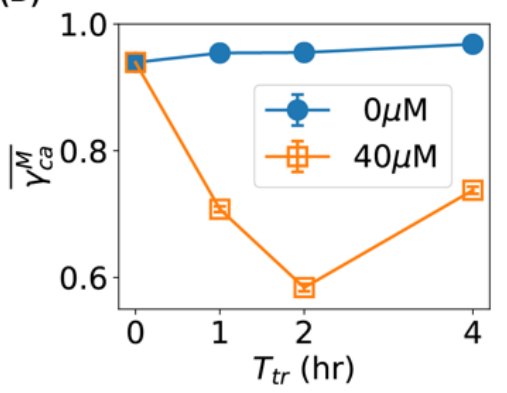

(F)

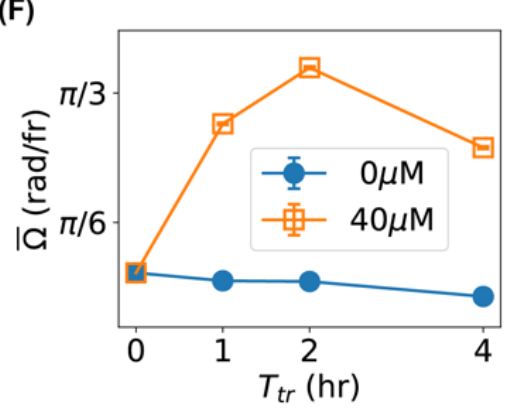

301

Figure 3. Characterization of bacterial movement and comparison between untreated and treated bacteria. (A, B) Autocorrelation of velocities (A: $\mathrm{v}_{\mathrm{x}} ; \mathrm{B}: \mathrm{v}_{\mathrm{y}}$ ) for bacteria treated with $\mathrm{Ag}^{+}$ ions at $40 \mu \mathrm{M}$ for $0,1,2$, and $4 \mathrm{hr}$. Insets: the corresponding results for untreated bacteria. (C) Cumulative distribution function (CDF) of the maximum chord-to-arc ratio $\left(\gamma_{C A}^{M}\right)$ for the trajectories of bacteria untreated ( $0 \mathrm{hr}$ ) or treated with $40 \mu \mathrm{M} \mathrm{Ag}^{+}$ions for 1,2 , and $4 \mathrm{hr}$. (D) Dependence of the mean of $\gamma_{C A}^{M}$ on treatment time. (E) CDF of the changing rate of swimming directions $(\Omega)$ for bacteria untreated $\left(0 \mathrm{hr}\right.$ ) or treated with $40 \mu \mathrm{M} \mathrm{Ag}^{+}$ions for 1,2 , and $4 \mathrm{hr}$. (F) Dependence of the mean of $\Omega$ on treatment time.

\section{Higher frequency of bacterial tumbling caused by $\mathrm{Ag}^{+}$ions}

To further understand the underlying mechanism of the inhibition of bacterial motility by $\mathrm{Ag}^{+}$ ions, we exploited the tethering assay on individual bacteria[46, 47]. Briefly, bacteria were tethered to clean glass coverslips through their flagella using biotinylated Anti-FliC antibody, neutravidin, and biotinylated bovine serum albumin (BSA) (Fig. 4A)[48]. The tethered bacteria 
would rotate on the glass surfaces as the flagellar motors rotate (Movie M3)[48, 64]. Between continuous rotations (i.e., running), occasional pauses and reversed rotations were observed, corresponding to the tumbling of the bacteria (Movie M4) $[65,66]$. After monitoring the rotation of the bacteria for 10,000 frames, $\mathrm{Ag}^{+}$ions were added into the samples at a final concentration of $40 \mu \mathrm{M}$. The rotation of the bacteria was then monitored for 50,000 to 100,000 frames. It was observed that the rotation of the bacteria slowed down, and that the frequency of pauses increased (Movie M4).
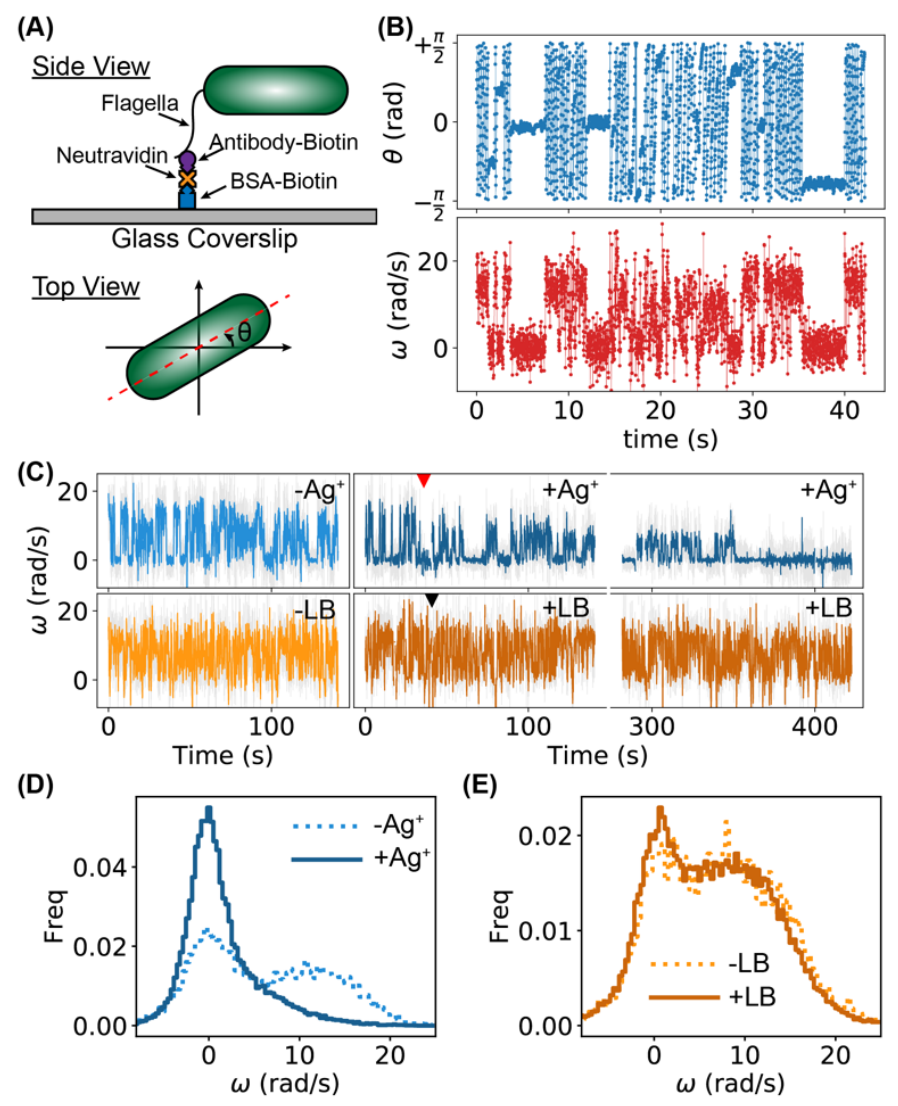

326

Figure 4. Tethering assay for investigating the running and tumbling of individual bacteria. (A) Tethering of a bacterium on a glass coverslip (side view), and orientation of a bacterium $\theta$ (top view). (B) Examples of trajectories of orientation $\theta$ and angular velocity $\omega$ of a bacterium for 3000 frames (or $42.3 \mathrm{~s}$ ). (C) Examples of $\omega$-trajectories for two bacteria. The top one was treated (blue curves) with $\mathrm{Ag}^{+}$ions; the red arrow indicates the time of adding $\mathrm{Ag}^{+}$ions. The bottom trajectories (orange curves) were for a bacterium without treatment. LB medium was added into the sample at the time indicated by the black arrow. (D) Distributions of $\omega$ for a bacterium treated by $\mathrm{Ag}^{+}$ions: pre- $\mathrm{Ag}^{+}$(dotted) and post- $\mathrm{Ag}^{+}$(solid). (E) Distributions of $\omega$ for an untreated bacterium: pre-LB (dotted) and post-LB (solid).

To quantify the results of the tethering assay, we first extracted the orientation of the bacteria, $\theta \in(-\pi / 2,+\pi / 2]$, in each frame of the movies; then the angular velocities of the bacterial rotations were calculated, $\omega=\Delta \theta / \Delta t$, where $\Delta \theta$ and $\Delta t=0.0141 \mathrm{~s}$ were the change of the bacterial orientation and time interval between adjacent frames, respectively. Examples of 
trajectories of $\theta$ and $\omega$ for 3,000 frames (or $42.3 \mathrm{~s}$ ) for a bacterium before $\mathrm{Ag}^{+}$-treatment are shown in Fig. 4B. Two distinct states were observed in the $\omega$-trajectory, presumably corresponding to the running and tumbling states $[65,66]$. The full $\omega$-trajectory $(10,000$ frames) of Fig. 4B is shown in Fig. 4C (-Ag+, light blue), while two segments (each with 10,000 frames) of the $\omega$-trajectory of the same bacterium during and after $\mathrm{Ag}^{+}$-treatment are also presented (Fig. $4 \mathrm{C},+\mathrm{Ag}^{+}$, dark blue), where the red arrow indicates the time of adding $\mathrm{Ag}^{+}$ions. It is clear that the tumbling state (i.e., lower angular velocity) became more frequent after $\mathrm{Ag}^{+}$-treatment. In contrast, untreated bacteria (adding LB medium instead of $\mathrm{Ag}^{+}$ions) did not show observable differences in the $\omega$-trajectories (Fig. $4 \mathrm{C}, \pm \mathrm{LB}$, light and dark orange). This observation was quantified by the distribution of the angular velocities. For the control, double peaks were observed for both before and after the addition of LB medium (Fig. 4E); in contrast, the tumbling peak (lower $\omega$ ) became dominant after the addition of $\mathrm{Ag}^{+}$ions (Fig. 4D). The observed increase in the tumbling frequency is consistent with a previous report based on swimming assays for the effect of Ag nanoparticles[28].

\section{Stalling of flagellar motors caused by $\mathrm{Ag}^{+}$ions}

To obtain a deeper understanding of why $\mathrm{Ag}^{+}$ions inhibit the bacterial movement and induce higher tumbling frequency, we performed hidden Markov model (HMM) analysis[55] on the trajectories of angular velocities from the tethering assay. It is noted that hidden Markov model is necessary because the motility states of the bacteria were not directly measured from the experiments; instead, the observable (i.e., the directly measured quantity) was the angular velocity $(\omega)$. Therefore, our hidden Markov model assumes two states: a running state $(R)$ and a tumbling state $(T)$, which emit observations of angular velocities (Fig. 5A). The probabilities for a bacterium to be in the running and tumbling states are $P_{R}$ and $P_{T}$, respectively. The bacterium can switch between the two states, with transition rates of $k_{R T}$ (from $\mathrm{R}$ to $\mathrm{T}$ ) and $k_{T R}$ (from $\mathrm{T}$ to $\mathrm{R})$. For a given time interval between observations $(\Delta t=0.0141 \mathrm{~s}$ between adjacent frames in the tethering assay), the transition probabilities would be $P_{R T}=k_{R T} \Delta t$ and $P_{T R}=k_{T R} \Delta t$, respectively. For each bacterium, we fitted/trained the $\mathrm{HMM}$ using the pre- $\mathrm{Ag}^{+}$or pre-LB data, and the fitted model was used to predict the states of all the observed angular velocities for that bacterium, which were then used to estimate the HMM parameters ( $P^{\prime} s$ and $k^{\prime} s$ ). As an example, the predicted states and the HMM parameters $\left(P_{R}, P_{T}, k_{R T}\right.$, and $\left.k_{T R}\right)$ for the $\pm \mathrm{Ag}^{+}$bacterium in Fig. $4 \mathrm{C}$ are presented in Figs. 5C and 5B, respectively. Two significant changes were observed. First, the tumbling probability $\left(P_{T}\right)$ increased dramatically from $49 \%$ to $87 \%$ (correspondingly, $P_{R}=1-P_{T}$ decreased); second, while the running-to-tumbling transition rate increased slightly, the tumbling-to-running transition rate $k_{T R}$ decreased significantly by $>4$-fold after $\mathrm{Ag}^{+}-$ treatment $\left(3.12 \mathrm{~s}^{-1}\right.$ to $0.75 \mathrm{~s}^{-1}$ ). These observations suggest that $\mathrm{Ag}^{+}$ions lead to higher tumbling frequency by blocking the transition from the tumbling state to the running state.

As simple and hidden Markov models typically assume exponential distributions for the dwell times (i.e., the time staying in the states), we wondered whether and how this assumption was satisfied in the tethering assay. Briefly, from the predicted states for the control and sample shown in Fig. $5 \mathrm{C}\left(+\mathrm{LB}\right.$ and $+\mathrm{Ag}^{+}$, respectively), we calculated the running time $\left(\tau_{r}\right)$ and tumbling 
time $\left(\tau_{t}\right)$ and found that the distributions of both dwell times followed roughly the exponential distribution for both the control (+LB) and the sample $\left(+\mathrm{Ag}^{+}\right)$, as shown in Fig. 5D, where the solid and dashed lines are fittings. This observation indicates that the hidden Markov model is reasonably suitable for the analysis here. On the other hand, we note that, a closer look on the distributions of the dwell times in the log-linear scale indicated that a single exponential decay did not fit the data well (Fig. 5E), suggesting that modified hidden Markov models that assume arbitrary distributions of the dwell times may improve the analysis.

(A)

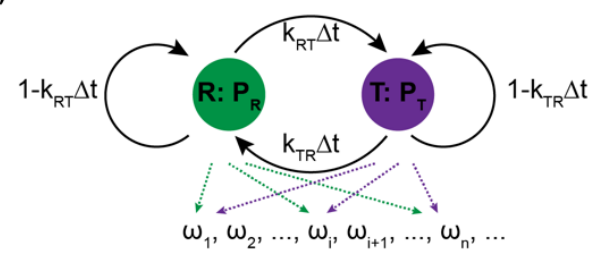

(B)

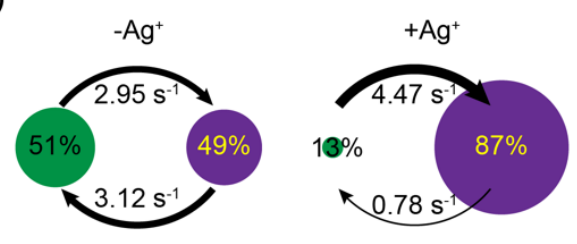

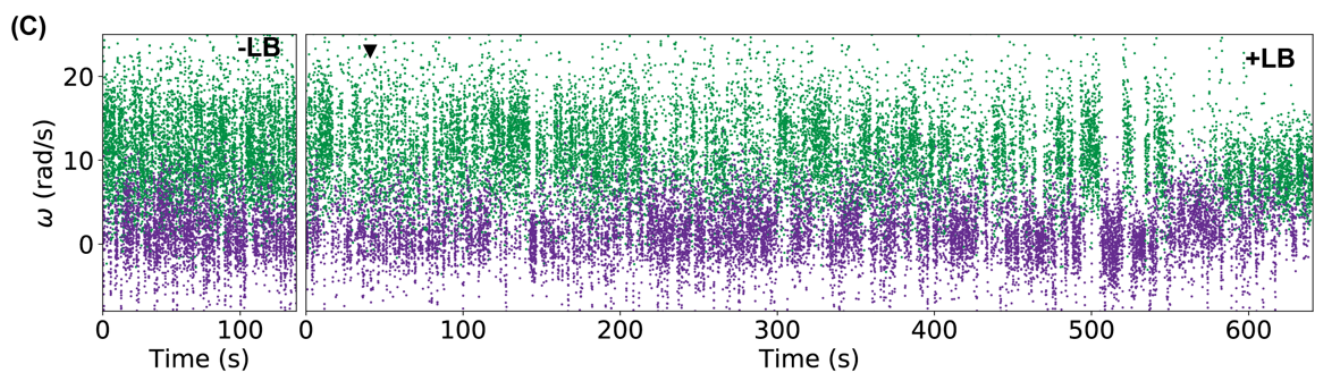

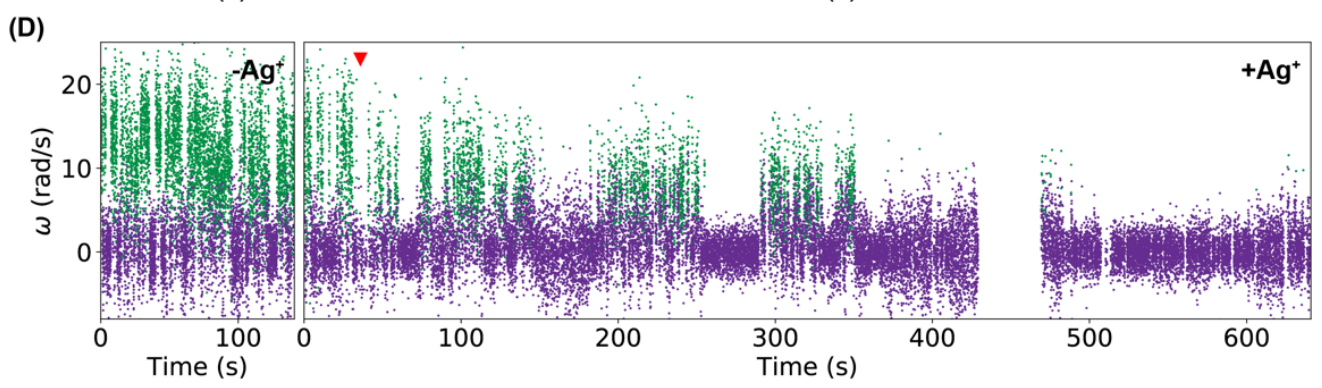

(E)

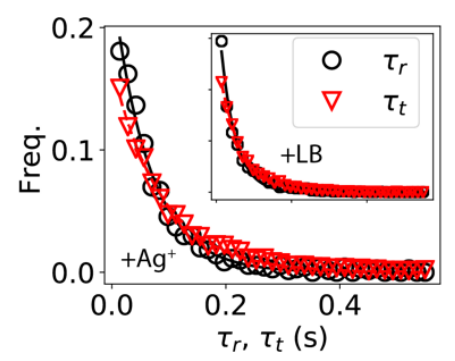

(F)

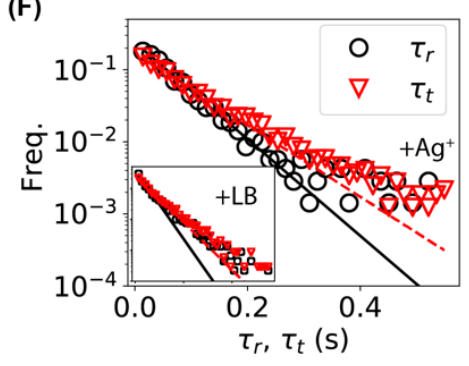

Figure 5. Hidden Markov model (HMM) analysis. (A) The hidden Markov model with two states (running (R) vs. tumbling (T)), which emit observations of angular velocities $\omega_{i}$. The probabilities for the system to be in the running and tumbling states are $P_{R}$ and $P_{T}$, respectively. The transition probabilities between the two states are $P_{R T}=k_{R T} \Delta t$ and $P_{T R}=k_{T R} \Delta t$, where $k_{R T}$ and $k_{T R}$ are the corresponding transition rates and $\Delta t$ is the time interval between observations. (B) 
trajectories of the bacterium in the top row of Fig. 4C. (C, D) Predictions of states from the fitted/trained HMM model for the angular velocity $(\omega)$ trajectories for $(C)$ an untreated bacterium and (D) an $\mathrm{Ag}^{+}$-treated bacterium. Green and purple dots correspond to the running and tumbling states, respectively. $(E, F)$ Distributions of the dwell times $\left(\tau_{r}\right.$ for running dwell time and $\tau_{t}$ for tumbling dwell time) from the (E) untreated and (F) Ag-treated bacteria shown in panels (C) and (D). Solid and dashed lines are fitted exponential curves. Insets: the same data plotted in loglinear scale.

We replicated the tethering assay experiments and $\mathrm{HMM}$ analysis on 10 untreated $( \pm \mathrm{LB})$ and 15 treated $\left( \pm \mathrm{Ag}^{+}\right)$bacteria. We observed large variations in the absolute values of the angular velocities for different bacteria, which could be attributed to differences in the cell length, the number of tethered flagella per bacterium, and the location of tethering points on the flagella[48, 67]. To compare among different bacteria, we used the relative changes in the HMM parameters, $\delta_{P_{T}}=\left(P_{T}^{+} / P_{T}^{-}-1\right) \times 100 \%$ and $\delta_{k_{T R}}=\left(k_{T R}^{+} / k_{T R}^{-}-1\right) \times 100 \%$, where the superscripts $(+$ and -) stand for after and before the addition of $\mathrm{Ag}^{+}$ions (or the addition of LB medium for the controls), respectively. The relative changes for the untreated (orange squares) and $\mathrm{Ag}^{+}$-treated bacteria (blue circles) from the full-length trajectories are shown in Fig. 6A. Performing onesample $t$-test showed that the increase in $P_{T}$ and decrease in $k_{T R}$ were much more statistically significant for the $\mathrm{Ag}^{+}$-treated bacteria ( $p$-values: $2.1 \times 10^{-4}$ and $4.1 \times 10^{-10}$ for $P_{T}$ and $k_{T R}$, respectively) than the untreated cells ( $p$-values: 0.065 and 0.014 , respectively). Two-sample $t$ test showed that the differences between the treated and untreated samples were also statistically significant (e.g., the $p$-value for $k_{T R}$ was $4.2 \times 10^{-4}$ ).

(A)

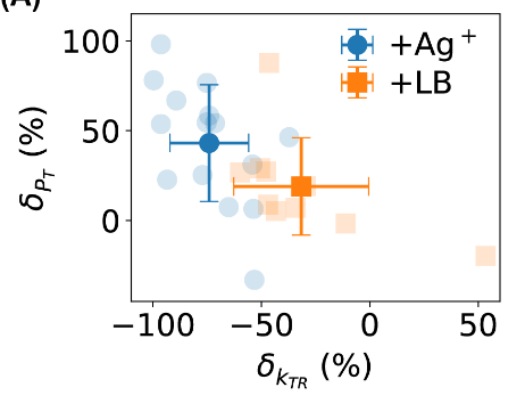

(B)

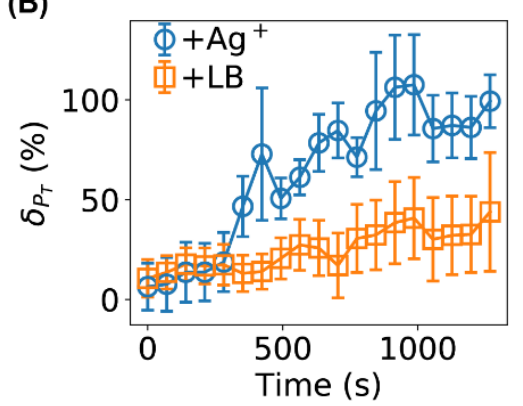

(C)

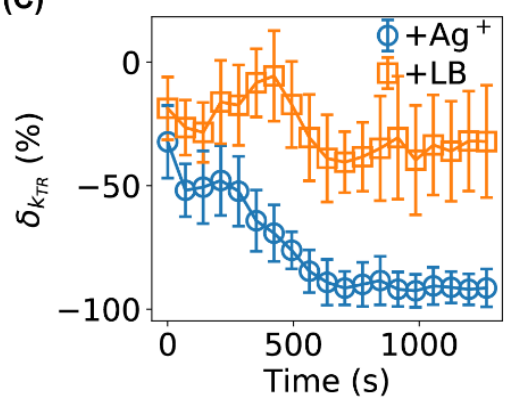

Figure 6. (A) Statistics of the relative changes in $P_{T}$ and $k_{T R}$ for 10 untreated (orange squares) and $15 \mathrm{Ag}^{+}$-treated bacteria (blue circles). Error bars stand for standard deviation. (B, C) Time dependencies of the relative changes in (B) $P_{T}$, and (C) $k_{T R}$ for untreated (orange squares) and $\mathrm{Ag}^{+}$-treated (blue circles) bacteria. Error bars stand for the standard error of the mean.

Finally, we examined the dependence of the HMM parameters on the treatment time (Figs. 6B and $6 \mathrm{C}$ ), which was done by analyzing individual segments of the full-length $\omega$-trajectories (window-size $=10,000$ frames, stride between segments $=5,000$ frames) using the fitted/trained HMM models. We observed that both $\delta_{P_{T}}$ and $\delta_{k_{T R}}$ started from $\approx 0$, which is reasonable as it takes time for the $\mathrm{Ag}^{+}$ions to diffuse to the bacteria and affect the bacteria. More interestingly, 
the effects of $\mathrm{Ag}^{+}$ions became more and more significant after $\sim 300 \mathrm{~s}$ compared to the controls (Figs. 6B and 6C). After $\sim 750 \mathrm{~s}$, the relative change of $k_{T R}$ reached $\sim-90 \%$, suggesting that $\mathrm{Ag}^{+}$ ions prevented the flagellar motor of the bacteria from rotating effectively and efficiently.

\section{Conclusions and Discussions}

To conclude, we directly visualized and investigated the antibiotic effects of $\mathrm{Ag}^{+}$ions on the motility of $E$. coli bacteria based on swimming and tethering assays. From the swimming assay, we observed that the bacteria slowed down dramatically when subjected to $\mathrm{Ag}^{+}$ions. Characterization of the swimming trajectories showed higher changing rates of swimming directions. In addition, we tethered the bacteria on glass surfaces through bacterial flagella (i.e., the tethering assay) and monitored the rotation of flagellar motors directly, from which we observed an increase in the tumbling frequency due to $\mathrm{Ag}^{+}$-treatment. We performed hidden Markov model (HMM) analysis on the trajectories of angular velocities of the bacterial rotation and compared the bacteria before and after $\mathrm{Ag}^{+}$-treatment. It was found that treated bacteria stayed in the tumbling state with much higher probability and that the transition rate from the tumbling state to the running state decreased in the presence of $\mathrm{Ag}^{+}$ions, suggesting that $\mathrm{Ag}^{+}$ ions stalled the flagellar motors and prevented them from rotating.

The observed inhibition of bacterial movement and higher frequency of tumbling caused by $\mathrm{Ag}^{+}$ ions confirmed our hypothesis that the motility of bacteria is significantly affected by $\mathrm{Ag}$. This work provides direct visualization of the Ag's effects on the bacterial movements and advances quantitatively our understanding on the mechanism of Ag-based antimicrobial agents in terms of bacterial motility. More importantly, it raises more interesting questions worth further investigations. For example, what is the molecular basis for the observed slower swimming, more frequent tumbling, and motor stalling, when subjecting bacteria to $\mathrm{Ag}^{+}$ions? To what extent the observed effects on the bacterial motility are Ag-specific? How will the bacteria adapt to, or become resistant against, the Ag-induced damages on the bacterial movement? How will bacterial death be related to the observed lower motility? Addressing these biological questions experimentally is expected to be of great importance and interest for understanding the fundamental antimicrobial mechanism of $\mathrm{Ag}$ and further exploring their potential biomedical applications.

Our data suggest that the observed effects of $\mathrm{Ag}^{+}$ions on the bacterial motility are likely due to direct interactions between the bacterial flagella and $\mathrm{Ag}^{+}$ions, which can be seen from the response time of the rotation of bacteria to the addition of $\mathrm{Ag}^{+}$ions (Fig. 6) in the tethering assays. In our tethering experiments, as the $\mathrm{Ag}^{+}$ions were added to the top surface of the liquid medium in the Petri-dish above the bacteria under observation, the distance that $\mathrm{Ag}^{+}$ions need to travel to the bacteria is roughly $\Delta x=0.2 \mathrm{~cm}$ (estimated from the volume of the culture medium, $2 \mathrm{~mL}$, and the diameter of the Petri-dish, $3.5 \mathrm{~cm}$ ). Considering that the diffusion coefficient of $\mathrm{Ag}^{+}$ions in water[68] is in the order of $D=1.5 \times 10^{-5} \mathrm{~cm}^{2} / \mathrm{s}$, the time scale for the $\mathrm{Ag}^{+}$ions to reach the bacteria is in the order of $\Delta t=\frac{\Delta x^{2}}{6 D} \approx 400 \mathrm{~s}$, which is close to the response time $(300-750 \mathrm{~s})$ of bacteria to the $\mathrm{Ag}^{+}$ions that we measured from our tethering assays (Fig. 6B and $6 \mathrm{C}$ ). If the 
478 observed effects of $\mathrm{Ag}^{+}$ions on the bacterial motility were due to indirect interactions, such as 479 those through regulatory proteins and membrane damages, the response time is expected to be 480 longer as time is needed to transduce those indirect effects to the flagellar motor. Therefore, it 481 is suggested to focus on the bacterial flagella when searching for molecular basis for the Ag482 caused slower swimming, more frequent tumbling, and motor stalling in future studies.

484 Acknowledgement

485

486 This work was supported by the University of Arkansas, the Arkansas Biosciences Institute, and 487 the National Science Foundation (Grant No. 1826642 to YW and JC). AR and MK were partially 488 supported by NSF-REU grants (Grant No. 1460754 and Grant No. 1851919). 


\section{References}

1. Davies, J. and Davies, D. "Origins and Evolution of Antibiotic Resistance." Microbiology and Molecular Biology Reviews 74, no. 3 (2010): 417-433. doi:10.1128/MMBR.00016-10, 2. Blair, J. M. A., Webber, M. A., Baylay, A. J., Ogbolu, D. O., and Piddock, L. J. V. "Molecular Mechanisms of Antibiotic Resistance." Nature Reviews. Microbiology 13, no. 1 (2015): 42-51. doi:10.1038/nrmicro3380,

3. CDC. "Antibiotic Resistance Threats in the United State" (2019):

4. Allen, H. K., Trachsel, J., Looft, T., and Casey, T. A. "Finding Alternatives to Antibiotics." Annals of the New York Academy of Sciences 1323, (2014): 91-100. doi:10.1111/nyas.12468, 42, no. 12 (2016): 2034-2036. doi:10.1007/s00134-016-4339-y, 6. Haque, M. A., Imamura, R., Brown, G. A., Krishnamurthi, V. R., Niyonshuti, I. I., Marcelle, T., Mathurin, L. E., Chen, J., and Wang, Y. "An Experiment-Based Model Quantifying Antimicrobial Activity of Silver Nanoparticles onEscherichia Coli" RSC Adv. 7, no. 89 (2017): 56173-56182. doi:10.1039/C7RA10495B, 7. Durán, N., Durán, M., Jesus, M. B. de, Seabra, A. B., Fávaro, W. J., and Nakazato, G. "Silver Nanoparticles: A New View on Mechanistic Aspects on Antimicrobial Activity." Nanomedicine : nanotechnology, biology, and medicine 12, no. 3 (2016): 789-799. doi:10.1016/j.nano.2015.11.016, Biotechnology advances 27, no. 1 (2009): 76-83. doi:10.1016/j.biotechadv.2008.09.002, 9. Jung, W. K., Koo, H. C., Kim, K. W., Shin, S., Kim, S. H., and Park, Y. H. "Antibacterial Activity and Mechanism of Action of the Silver Ion in Staphylococcus Aureus and Escherichia Coli." Applied and Environmental Microbiology 74, no. 7 (2008): 2171-2178. doi:10.1128/AEM.0200107, 10. Feng, Q. L., Wu, J., Chen, G. Q., Cui, F. Z., Kim, T. N., and Kim, J. O. "A Mechanistic Study of the Antibacterial Effect of Silver Ions on Escherichia Coli and Staphylococcus Aureus." Journal of Biomedical Materials Research 52, no. 4 (2000): 662-668. doi:10.1002/10974636(20001215)52:4<662::AID-JBM10>3.0.CO;2-3, 11. Radzig, M. A., Nadtochenko, V. A., Koksharova, O. A., Kiwi, J., Lipasova, V. A., and Khmel, I. A. "Antibacterial Effects of Silver Nanoparticles on Gram-Negative Bacteria: Influence on the Growth and Biofilms Formation, Mechanisms of Action." Colloids and Surfaces. B, Biointerfaces 102, (2013): 300-306. doi:10.1016/j.colsurfb.2012.07.039,

12. Marambio-Jones, C. and Hoek, E. M. V. "A Review of the Antibacterial Effects of Silver Nanomaterials and Potential Implications for Human Health and the Environment" Journal of nanoparticle research : an interdisciplinary forum for nanoscale science and technology 12, no. 5 (2010): 1531-1551. doi:10.1007/s11051-010-9900-y, 13. Ivask, A., Elbadawy, A., Kaweeteerawat, C., Boren, D., Fischer, H., Ji, Z., Chang, C. H., Liu, R., Tolaymat, T., Telesca, D., Zink, J. I., Cohen, Y., Holden, P. A., and Godwin, H. A. "Toxicity Mechanisms in Escherichia Coli Vary for Silver Nanoparticles and Differ from lonic Silver." ACS Nano 8, no. 1 (2014): 374-386. doi:10.1021/nn4044047, 
14. Sadoon, A. A., Khadka, P., Freeland, J., Gundampati, R. K., Manso, R., Ruiz, M., Krishnamurthi, V. R., Thallapuranam, S. K., Chen, J., and Wang, Y. "Faster Diffusive Dynamics of Histone-like Nucleoid Structuring Proteins in Live Bacteria Caused by Silver Ions." Applied and Environmental Microbiology (2020): doi:10.1128/AEM.02479-19, 15. Krishnamurthi, V. R., Chen, J., and Wang, Y. "Silver lons Cause Oscillation of Bacterial Length of Escherichia Coli." Scientific Reports 9, no. 1 (2019): 11745. doi:10.1038/s41598-019-48113-4, 16. Josenhans, C. and Suerbaum, S. "The Role of Motility as a Virulence Factor in Bacteria." International Journal of Medical Microbiology 291, no. 8 (2002): 605-614. doi:10.1078/14384221-00173,

17. Sowa, Y. and Berry, R. M. "Bacterial Flagellar Motor." Quarterly Reviews of Biophysics 41, no. 2 (2008): 103-132. doi:10.1017/S0033583508004691, 18. Zhao, Z., Zhao, Y., Zhuang, X.-Y., Lo, W.-C., Baker, M. A. B., Lo, C.-J., and Bai, F. "Frequent Pauses in Escherichia Coli Flagella Elongation Revealed by Single Cell Real-Time Fluorescence Imaging." Nature Communications 9, no. 1 (2018): 1885. doi:10.1038/s41467-018-04288-4, 19. Minamino, T. and Imada, K. "The Bacterial Flagellar Motor and Its Structural Diversity." Trends in Microbiology 23, no. 5 (2015): 267-274. doi:10.1016/j.tim.2014.12.011, 20. Parkinson, J. S., Hazelbauer, G. L., and Falke, J. J. "Signaling and Sensory Adaptation in Escherichia Coli Chemoreceptors: 2015 Update." Trends in Microbiology 23, no. 5 (2015): 257266. doi:10.1016/j.tim.2015.03.003, 21. Sourjik, V. and Wingreen, N. S. "Responding to Chemical Gradients: Bacterial Chemotaxis." Current Opinion in Cell Biology 24, no. 2 (2012): 262-268. doi:10.1016/j.ceb.2011.11.008, 22. Gugala, N., Lemire, J., Chatfield-Reed, K., Yan, Y., Chua, G., and Turner, R. J. "Using a Chemical Genetic Screen to Enhance Our Understanding of the Antibacterial Properties of Silver." Genes 9, no. 7 (2018): doi:10.3390/genes9070344, 23. Alqahtany, M., Khadka, P., Niyonshuti, I., Krishnamurthi, V. R., Sadoon, A. A., Challapalli, S. D., Chen, J., and Wang, Y. "Nanoscale Reorganizations of Histone-like Nucleoid Structuring Proteins in Escherichia Coli Are Caused by Silver Nanoparticles." Nanotechnology 30, no. 38 (2019): 385101. doi:10.1088/1361-6528/ab2a9f, 24. Wang, H., Ayala, J. C., Benitez, J. A., and Silva, A. J. "RNA-Seq Analysis Identifies New Genes Regulated by the Histone-like Nucleoid Structuring Protein (H-NS) Affecting Vibrio Cholerae doi:10.1371/journal.pone.0118295,

25. Bertin, P., Terao, E., Lee, E. H., Lejeune, P., Colson, C., Danchin, A., and Collatz, E. "The H-NS Protein Is Involved in the Biogenesis of Flagella in Escherichia Coli." Journal of Bacteriology 176, no. 17 (1994): 5537-5540.

26. Garuglieri, E., Cattò, C., Villa, F., Zanchi, R., and Cappitelli, F. "Effects of Sublethal Concentrations of Silver Nanoparticles on Escherichia Coli and Bacillus Subtilis under Aerobic and Anaerobic Conditions." Biointerphases 11, no. 4 (2016): 04B308. doi:10.1116/1.4972100, 27. West, M., Burdash, N. M., and Freimuth, F. "Simplified Silver-Plating Stain for Flagella." Journal of Clinical Microbiology 6, no. 4 (1977): 414-419.

28. Ortega-Calvo, J.-J., Molina, R., Jimenez-Sanchez, C., Dobson, P. J., and Thompson, I. P. "Bacterial Tactic Response to Silver Nanoparticles." Environmental microbiology reports 3, no. 5 (2011): 526-534. doi:10.1111/j.1758-2229.2011.00252.x, 
29. Choi, O., Deng, K. K., Kim, N.-J., Ross, L., Surampalli, R. Y., and Hu, Z. "The Inhibitory Effects of Silver Nanoparticles, Silver Ions, and Silver Chloride Colloids on Microbial Growth." Water Research 42, no. 12 (2008): 3066-3074. doi:10.1016/j.watres.2008.02.021, 30. Mazouchi, A. and Milstein, J. N. "Fast Optimized Cluster Algorithm for Localizations (FOCAL): A Spatial Cluster Analysis for Super-Resolved Microscopy." Bioinformatics 32, no. 5 (2016): 747754. doi:10.1093/bioinformatics/btv630, 31. Sadoon, A. A. and Wang, Y. "Anomalous, Non-Gaussian, Viscoelastic, and Age-Dependent Dynamics of Histonelike Nucleoid-Structuring Proteins in LiveEscherichia Coli" Physical Review E 98, no. 4 (2018): 042411. doi:10.1103/PhysRevE.98.042411, 32. Zhang, M., Chang, H., Zhang, Y., Yu, J., Wu, L., Ji, W., Chen, J., Liu, B., Lu, J., Liu, Y., Zhang, J., $\mathrm{Xu}, \mathrm{P} .$, and $\mathrm{Xu}, \mathrm{T}$. "Rational Design of True Monomeric and Bright Photoactivatable Fluorescent Proteins." Nature Methods 9, no. 7 (2012): 727-729. doi:10.1038/nmeth.2021, 33. Tang, H. and Blair, D. F. "Regulated Underexpression of the FliM Protein of Escherichia Coli and Evidence for a Location in the Flagellar Motor Distinct from the MotA/MotB Torque Generators." Journal of Bacteriology 177, no. 12 (1995): 3485-3495. doi:10.1128/jb.177.12.3485-3495.1995,

34. Berg, H. C. and Brown, D. A. "Chemotaxis in Escherichia Coli Analysed by Three-Dimensional Tracking." Nature 239, no. 5374 (1972): 500-504. doi:10.1038/239500a0, 35. Del Tito, B. J., Ward, J. M., Hodgson, J., Gershater, C. J., Edwards, H., Wysocki, L. A., Watson, F. A., Sathe, G., and Kane, J. F. "Effects of a Minor Isoleucyl TRNA on Heterologous Protein Translation in Escherichia Coli." Journal of Bacteriology 177, no. 24 (1995): 7086-7091. doi:10.1128/jb.177.24.7086-7091.1995, 36. Edelstein, A., Amodaj, N., Hoover, K., Vale, R., and Stuurman, N. "Computer Control of Microscopes Using MManager." Current Protocols in Molecular Biology Chapter 14, (2010): Unit14.20. doi:10.1002/0471142727.mb1420s92, 37. Edelstein, A. D., Tsuchida, M. A., Amodaj, N., Pinkard, H., Vale, R. D., and Stuurman, N. "Advanced Methods of Microscope Control Using MManager Software." Journal of biological methods 1, no. 2 (2014): doi:10.14440/jbm.2014.36, 38. Schindelin, J., Arganda-Carreras, I., Frise, E., Kaynig, V., Longair, M., Pietzsch, T., Preibisch, S., Rueden, C., Saalfeld, S., Schmid, B., Tinevez, J.-Y., White, D. J., Hartenstein, V., Eliceiri, K., Tomancak, P., and Cardona, A. "Fiji: An Open-Source Platform for Biological-Image Analysis." Nature Methods 9, no. 7 (2012): 676-682. doi:10.1038/nmeth.2019,

39. Schneider, C. A., Rasband, W. S., and Eliceiri, K. W. "NIH Image to Image J: 25 Years of Image Analysis." Nature Methods 9, no. 7 (2012): 671-675. doi:10.1038/nmeth.2089, 40. Crocker, J. C. and Grier, D. G. "Methods of Digital Video Microscopy for Colloidal Studies" Journal of Colloid and Interface Science 179, no. 1 (1996): 298-310. doi:10.1006/jcis.1996.0217, 41. Stracy, M., Lesterlin, C., Garza de Leon, F., Uphoff, S., Zawadzki, P., and Kapanidis, A. N. "LiveCell Superresolution Microscopy Reveals the Organization of RNA Polymerase in the Bacterial Nucleoid." Proceedings of the National Academy of Sciences of the United States of America 112, no. 32 (2015): E4390-9. doi:10.1073/pnas.1507592112,

617 42. Allan, D. B., Caswell, T., Keim, N. C., and Wel, C. M. van der. "Trackpy: Trackpy V0.4.1" Zenodo (2018): doi:10.5281/zenodo.1226458, 
43. Pottash, A. E., McKay, R., Virgile, C. R., Ueda, H., and Bentley, W. E. "TumbleScore: Run and Tumble Analysis for Low Frame-Rate Motility Videos." Biotechniques 62, no. 1 (2017): 31-36. doi:10.2144/000114493, of Swimming Behavior in Peritrichously Flagellated Bacteria." Analytical Biochemistry 235, no. 1 (1996): 20-25. doi:10.1006/abio.1996.0086, 45. Alon, U., Camarena, L., Surette, M. G., Aguera y Arcas, B., Liu, Y., Leibler, S., and Stock, J. B. "Response Regulator Output in Bacterial Chemotaxis." The EMBO Journal 17, no. 15 (1998): 4238-4248. doi:10.1093/emboj/17.15.4238, 46. Schniederberend, M., Abdurachim, K., Murray, T. S., and Kazmierczak, B. I. "The GTPase Activity of FlhF Is Dispensable for Flagellar Localization, but Not Motility, in Pseudomonas Aeruginosa." Journal of Bacteriology 195, no. 5 (2013): 1051-1060. doi:10.1128/JB.02013-12, 47. Schniederberend, M., Williams, J. F., Shine, E., Shen, C., Jain, R., Emonet, T., and Kazmierczak, B. I. "Modulation of Flagellar Rotation in Surface-Attached Bacteria: A Pathway for Rapid Surface-Sensing after Flagellar Attachment." PLoS Pathogens 15, no. 11 (2019): e1008149. doi:10.1371/journal.ppat.1008149, 48. Inoue, Y. "Rotation Measurements of Tethered Cells." Methods in Molecular Biology 1593, (2017): 163-174. doi:10.1007/978-1-4939-6927-2_12, 49. Da Silva, S., Grosjean, L., Ternan, N., Mailley, P., Livache, T., and Cosnier, S. "Biotinylated Polypyrrole Films: An Easy Electrochemical Approach for the Reagentless Immobilization of Bacteria on Electrode Surfaces." Bioelectrochemistry 63, no. 1-2 (2004): 297-301. doi:10.1016/j.bioelechem.2003.09.027, 50. Kim, J.-S., Kim, Y. J., Seo, S., Seong, M.-J., and Lee, K. "Functional Role of Bdm during Flagella Biogenesis in Escherichia Coli." Current Microbiology 70, no. 3 (2015): 369-373. doi:10.1007/s00284-014-0729-y, 51. Francis, N. R., Sosinsky, G. E., Thomas, D., and DeRosier, D. J. “Isolation, Characterization and Structure of Bacterial Flagellar Motors Containing the Switch Complex." Journal of Molecular Biology 235, no. 4 (1994): 1261-1270. doi:10.1006/jmbi.1994.1079, 52. Walt, S. van der, Schönberger, J. L., Nunez-Iglesias, J., Boulogne, F., Warner, J. D., Yager, N., Gouillart, E., Yu, T., and scikit-image contributors. "Scikit-Image: Image Processing in Python." PeerJ 2, (2014): e453. doi:10.7717/peerj.453, 53. Patteson, A. E., Gopinath, A., Goulian, M., and Arratia, P. E. "Running and Tumbling with E. Coli in Polymeric Solutions." Scientific Reports 5, (2015): 15761. doi:10.1038/srep15761, 54. Cheong, F. C., Wong, C. C., Gao, Y., Nai, M. H., Cui, Y., Park, S., Kenney, L. J., and Lim, C. T. "Rapid, High-Throughput Tracking of Bacterial Motility in 3D via Phase-Contrast Holographic Video Microscopy." Biophysical Journal 108, no. 5 (2015): 1248-1256. doi:10.1016/j.bpj.2015.01.018, 55. Korobkova, E. A., Emonet, T., Park, H., and Cluzel, P. "Hidden Stochastic Nature of a Single Bacterial Motor." Physical Review Letters 96, no. 5 (2006): 058105.

658 56. Persson, F., Lindén, M., Unoson, C., and Elf, J. "Extracting Intracellular Diffusive States and 659 Transition Rates from Single-Molecule Tracking Data." Nature Methods 10, no. 3 (2013): 265660 269. doi:10.1038/nmeth.2367, 
57. Theves, M., Taktikos, J., Zaburdaev, V., Stark, H., and Beta, C. “A Bacterial Swimmer with Two Alternating Speeds of Propagation." Biophysical Journal 105, no. 8 (2013): 1915-1924. doi:10.1016/j.bpj.2013.08.047, 58. Theves, M., Taktikos, J., Zaburdaev, V., Stark, H., and Beta, C. "Random Walk Patterns of a Soil Bacterium in Open and Confined Environments" EPL (Europhysics Letters) 109, no. 2 (2015): 28007. doi:10.1209/0295-5075/109/28007, 59. Lauga, E., DiLuzio, W. R., Whitesides, G. M., and Stone, H. A. "Swimming in Circles: Motion of Bacteria near Solid Boundaries." Biophysical Journal 90, no. 2 (2006): 400-412. doi:10.1529/biophysj.105.069401, 60. Boulos, L., Prévost, M., Barbeau, B., Coallier, J., and Desjardins, R. "LIVE/DEAD BacLight : Application of a New Rapid Staining Method for Direct Enumeration of Viable and Total Bacteria in Drinking Water." Journal of Microbiological Methods 37, no. 1 (1999): 77-86. doi:10.1016/S0167-7012(99)00048-2, 61. Michalet, X. "Mean Square Displacement Analysis of Single-Particle Trajectories with Localization Error: Brownian Motion in an Isotropic Medium." Physical Review. E, Statistical, Nonlinear, and Soft Matter Physics 82, no. 4 Pt 1 (2010): 041914. doi:10.1103/PhysRevE.82.041914,

678 62. Metzler, R., Jeon, J.-H., Cherstvy, A. G., and Barkai, E. “Anomalous Diffusion Models and Their Properties: Non-Stationarity, Non-Ergodicity, and Ageing at the Centenary of Single Particle Tracking." Physical Chemistry Chemical Physics 16, no. 44 (2014): 24128-24164. doi:10.1039/c4cp03465a, 63. Metzler, R. and Klafter, J. "The Random Walk's Guide to Anomalous Diffusion: A Fractional Dynamics Approach" Physics Reports 339, no. 1 (2000): 1-77. doi:10.1016/S03701573(00)00070-3, 64. Qian, C., Wong, C. C., Swarup, S., and Chiam, K.-H. "Bacterial Tethering Analysis Reveals a 'Run-Reverse-Turn' Mechanism for Pseudomonas Species Motility." Applied and Environmental Microbiology 79, no. 15 (2013): 4734-4743. doi:10.1128/AEM.01027-13, 65. Manson, M. D. "Dynamic Motors for Bacterial Flagella." Proceedings of the National Academy of Sciences of the United States of America 107, no. 25 (2010): 11151-11152. doi:10.1073/pnas.1006365107, 66. Dominick, C. N. and Wu, X.-L. "Rotating Bacteria on Solid Surfaces without Tethering." Biophysical Journal 115, no. 3 (2018): 588-594. doi:10.1016/j.bpj.2018.06.020, 67. Lele, P. P., Hosu, B. G., and Berg, H. C. "Dynamics of Mechanosensing in the Bacterial Flagellar Motor." Proceedings of the National Academy of Sciences of the United States of America 110, no. 29 (2013): 11839-11844. doi:10.1073/pnas.1305885110, 68. Johnston, R. R. M. and Spiro, M. "Diffusion Coefficients of the Silver Ion and the Disulfitosilver (I) lon by the Rotating Disk Method" The Journal of physical chemistry 71, no. 12 